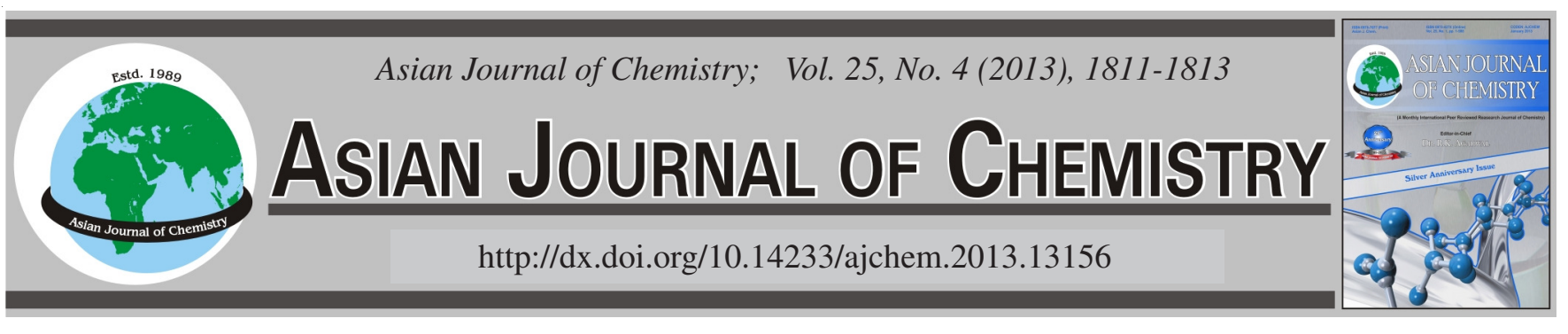

\title{
Application of Avrami Equation to Kinetics Analysis of Fly Ash Based Linde F (K) Zeolite
}

\author{
C. CHEN $^{1, *}$ and T. CHENG ${ }^{2}$
}

${ }^{1}$ School of Biology and Chemical Engineering, Jiangsu University of Science and Technology, Zhenjiang 212018, P.R. China ${ }^{2}$ Department of City Science, Jiangsu City Vocational College, Nanjing 210036, P.R. China

*Corresponding author: Tel: +86 25 85605157; E-mail: chenchen19830515@gmail.com

(Received: 1 December 2011;

Accepted: 3 October 2012)

AJC-12225

\begin{abstract}
Avrami equation was applied to model the formation process of fly ash based Linde F (K) zeolite. The results showed that: (1) Linde F (K) zeolite could be gained through the reaction between fly ash and potassium hydroxide solutions and temperature seriously affected the reaction rate. (2) Avrami equation could be successfully used to analysis the kinetics process of Linde F (K) zeolite growth. (3) The formation of model of this zeolite is heterogeneous and the crystalline is linear growth. (4) The activation energy of zeolite crystalline and nucleation is about 134.5 and $85.4 \mathrm{~kJ} / \mathrm{mol}$, respectively.
\end{abstract}

Key Words: Avrami equation, Fly ash, Kinetics, Zeolite.

ᄂ - - - - - - - - - - - - - - - - - - - - - - - - - - - - -

\section{INTRODUCTION}

Fly ash is a solid waste produced by power plant. With the development of economic, the total mass of fly ash all over the world was increasing year by year. In 2009, China produced 45 million tons fly ash and only $30 \%$ have been reused $^{1}$. Storage of these un-used fly ash occupied lots of cultivated land and the pollutions of fly ash has become one of Chinese serious environmental problems. On the other hand, zeolite is a type of silica and aluminum based mineral which has many applications. Many researchers have suggested that fly ash could be used as a resources material for zeolite synthesis and many fly ash based zeolite have been found ${ }^{2,3}$. Many articles even advised the mechanism and kinetics of formation process of fly ash based zeolite ${ }^{4,5}$ and some of the zeolite were successfully used for waste water adsorption treatment ${ }^{6,7}$.

However, most of the studies focus on the zeolite synthesis in sodium hydroxide systems. The papers discussed the potassium hydroxide systems were very few ${ }^{8}$ and nearly no paper was discussed the kinetics process. This paper chose Linde $F(K)$ as research object and focus on the growth kinetics of this zeolite. The kinetics equations used in this paper were called Avrami equation which was proposed by Melvin Avrami in $1930 \mathrm{~s}^{9,10}$. The equations has been applied by many researchers to explain the formation process of new crystalline and proved that the equation could give us a best describe about the kinetics process including zeolite. The results of the paper could provide a basic understanding of reaction mechanism and growth kinetics of potassium hydroxide based zeolite.

\section{EXPERIMENTAL}

Fly ash used in this experiment was obtained from Taicang harbour golden concord electric-power generation Co. Ltd (Taicang, Jiangsu province), China. The chemical composition was showed in Table-1. As Table-1, the main composition of fly ash sample was silica and aluminum oxide. The alkaline solutions were prepared by potassium hydroxide (AR) and deionized water. The concentrations were $10 \mathrm{M}$. Every solution was prepared one day before used.

The zeolite synthesis experiments were conducted by mixing fly ash particles and $\mathrm{KOH}$ solution (Mass ratioliquid/solid $=20$ ) in Teflon bottles. The reaction time was from 1-336 h. The reaction temperature is from $50-90^{\circ} \mathrm{C}$. After reaction, the mixtures were filtered and solids were dry under $105^{\circ} \mathrm{C}$ to constant weight. Finally, the solid were detected by Q-XRD system in order to determine the mass of zeolite and the data were all normalized to $1 \mathrm{~g}$ original fly ash.

TABLE-1

\begin{tabular}{ccccccccccccc}
\multicolumn{10}{c}{ TABLE-1 } \\
\multicolumn{10}{c}{ CHEMICAL COMPOSITION OF FLY ASH SAMPLE } \\
\hline Oxides & $\mathrm{SiO}_{2}$ & $\mathrm{Al}_{2} \mathrm{O}_{3}$ & $\mathrm{CaO}$ & $\mathrm{Fe}_{2} \mathrm{O}_{3}$ & $\mathrm{Na}_{2} \mathrm{O}$ & $\mathrm{MgO}$ & $\mathrm{K}_{2} \mathrm{O}$ & $\mathrm{TiO}_{2}$ & $\mathrm{P}_{2} \mathrm{O}_{5}$ & $\mathrm{LOI}^{\mathrm{a}}$ \\
\hline Fly ash & 45.1 & 23.3 & 0.34 & 8.74 & 0.19 & 0.58 & 1.23 & 2.04 & 0.47 & 10.1 \\
\hline
\end{tabular}

${ }^{a} \mathrm{LOI}$ loss on ignition at $960^{\circ} \mathrm{C}$. 
Kinetics equations: The equations used in present paper were showed as eqns. 1 and 2 (linear form).

$$
\begin{gathered}
\alpha=1-\exp \left(1-\mathrm{kt}^{\mathrm{n}}\right) \\
\ln [-\ln (1-\alpha)]=\mathrm{n} \ln (\mathrm{t})+(\mathrm{k})
\end{gathered}
$$

here, " $\alpha$ " is mass of zeolite normalized to $1 \mathrm{~g}$ original fly ash. " $k$ " is reaction rate. " $t$ " is reaction time. " $n$ " is reaction order.

$$
\begin{gathered}
\mathrm{k}=\mathrm{A} \exp \left(\frac{-\mathrm{E}_{\mathrm{a}}}{\mathrm{RT}}\right) \\
\ln (\mathrm{k})=\frac{-\mathrm{E}_{\mathrm{a}}}{\mathrm{RT}}+\ln (\mathrm{A}) \\
\frac{1}{\mathrm{t}_{0}}=\mathrm{B} \exp \left(\frac{-\mathrm{E}_{0}}{\mathrm{RT}}\right) \\
\ln \left(\mathrm{t}_{0}\right)=\frac{\mathrm{E}_{0}}{\mathrm{RT}}-\ln (\mathrm{B})
\end{gathered}
$$

here, " $\mathrm{k}$ " is reaction rate. "T" is absolute temperature. " $\mathrm{t}_{0}$ " is induction period. " $\mathrm{E}_{\mathrm{a}}$ " and " $\mathrm{E}_{0}$ " were activation energy of zeolite crystalline and nucleation.

\section{RESULTS AND DISCUSSION}

Zeolite synthesis: Fig. 1 showed the XRD and SEM results of original fly ash and reaction products. As Fig. 1, only the crystalline peaks of quartz and mullite could be found in XRD pattern of original fly ash. Besides these, a halo peak which resources from glass phase could be observed in $2 \theta$ from $20-30^{\circ}$. After reaction with $\mathrm{KOH}$ solution, some new peaks which belonged to Linde $\mathrm{F}(\mathrm{K})$ zeolite were observed. At the same time, the surfaces of sphere fly ash particles were covered with lots of tetrahedron crystalline. All of these implied that Linde $\mathrm{F}(\mathrm{K})$ zeolite has been successfully synthesized on the surface of fly ash particles.
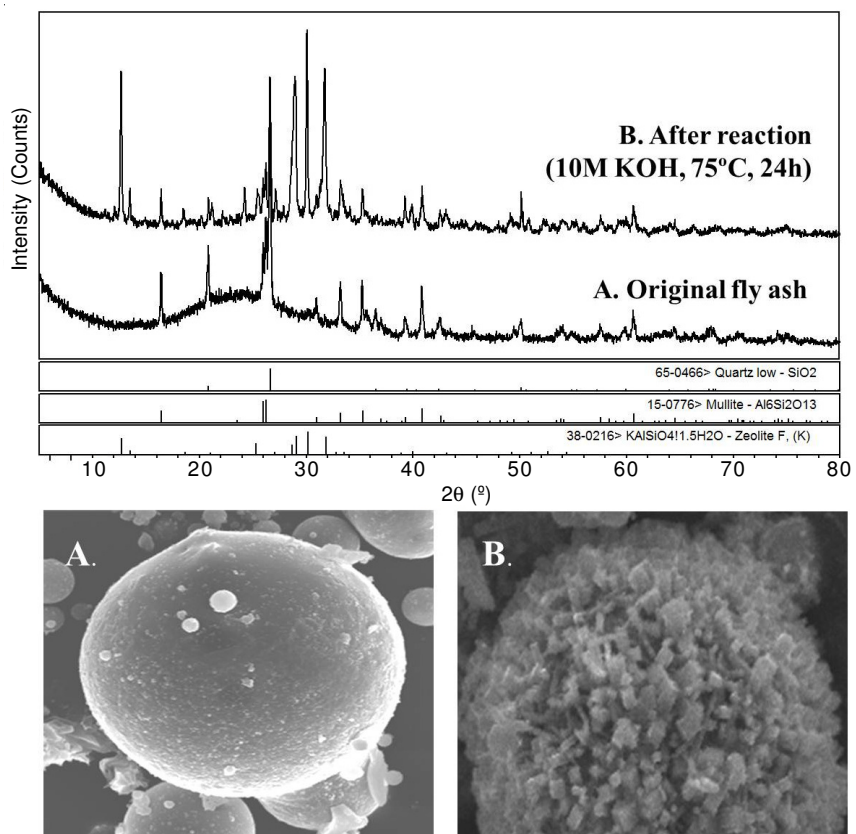

Fig. 1. XRD patterns and SEM images of original fly ash and reaction products
Temperature dependence: Fig. 2 shows how temperature affects the formation process of zeolite. From Fig. 2, we could receive information that temperature was one of important factors for formation process. Under $90{ }^{\circ} \mathrm{C}, 0.32$ and $0.59(/ 1 \mathrm{~g}$ original fly ash) zeolite could be gained after 72 and $336 \mathrm{~h}$. At the same time, the mass of zeolite only could reach 0.22 and 0.42 (/1 g original fly ash) and 0 and 0.48 (/1 g original fly ash) under 75 and $50{ }^{\circ} \mathrm{C}$, respectively. On the other hand, Fig. 2 showed that there exit an induction period before the appearance of zeolite under every temperature and the periods were shortened with temperature increasing. For example, under $50^{\circ} \mathrm{C}$, no zeolite formed until the time reach $84 \mathrm{~h}$ while the induction period of other three temperatures were $72 \mathrm{~h}, 9$ and $3 \mathrm{~h}$, respectively. As we know, during induction period, glass phase in fly ash dissolved to "free" silica and aluminum. So, according to Fig. 2, increasing the temperature also could improve the rate of fly ash dissolving.

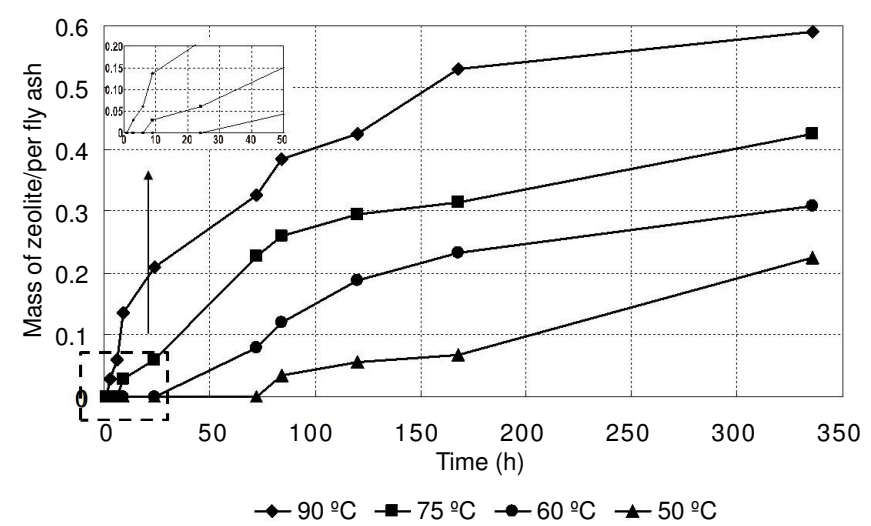

Fig. 2. Change of mass of zeolite (per $1 \mathrm{~g}$ original fly ash) as a function of temperature

Kinetics analysis: The data in Fig. 2 have been plotted by Avrami equations and the results are showed in Fig. 3 and Table-2. As Fig. 3, the Avrami equation was successfully used for the formation process of fly ash based zeolite. The reaction rate of Avrami equation was increasing with the temperature. The order of reaction rate is $90{ }^{\circ} \mathrm{C}(0.207)>75^{\circ} \mathrm{C}(0.00504)$ $>60{ }^{\circ} \mathrm{C}(0.001008)>50{ }^{\circ} \mathrm{C}(0.000065)$. On the other hand, the value of " $n$ " in the Avrami equation could give us some information about the mechanism ${ }^{9,10}$. The value of " $n$ " should be in the range of 1 to 5 and the values were the sum of two other parameters $\left(\mathrm{n}_{1}\right.$ and $\left.\mathrm{n}_{2}\right)$. The value of $\mathrm{n}_{1}$ could be either 0 or 1 . If the formation process is homogenous and the crystalline core must form inside the solution, the $\mathrm{n}_{1}$ was 1 . Otherwise, if the formation process is heterogeneous and the crystalline core was supplied from other way, the $n_{1}$ was 0 . The value of $n_{2}$ comes from the forming model of zeolite. The $\mathrm{n}_{2}$ could be 1 , 2, 3 and 4 when the forming model is linear, surface and threedimensional growth ${ }^{9,10}$. As Table-2, the value of " $n$ " in our experiment is around 1 . This suggested that the type of forming model is heterogeneous $\left(\mathrm{n}_{1}=0\right)$ and the crystalline is liner growth $\left(\mathrm{n}_{2}=1\right)$. From SEM images we could obtain that the tetragonal zeolite crystalline formed on the surface of fly ash particles. So, we could presume that the forming model for fly ash based zeolite is a typical heterogeneous process. Sphere fly ash particles supplied plentiful precipitation surface and 


\begin{tabular}{ccccccc}
\hline \multicolumn{7}{c}{ TABLE-2 } \\
KINETICS PARAMETERS \\
\hline No. & $\begin{array}{c}\text { Temp. } \\
\left({ }^{\circ} \mathrm{C}\right)\end{array}$ & $\mathrm{k}$ & $\mathrm{n}$ & $\begin{array}{c}\mathrm{E}_{\mathrm{a}} \\
(\mathrm{kJ} / \mathrm{mol})\end{array}$ & $\begin{array}{c}\mathrm{E}_{0} \\
(\mathrm{~kJ} / \mathrm{mol})\end{array}$ & $\mathrm{R}_{2}$ \\
\hline 1 & 50 & 0.020700 & 1.05 & & & 0.96 \\
2 & 60 & 0.005048 & 1.13 & 134.5 & 85.4 & 0.98 \\
3 & 75 & 0.001008 & 0.97 & & & 0.95 \\
4 & 90 & 0.000065 & 1.07 & & & 0.96 \\
\hline
\end{tabular}

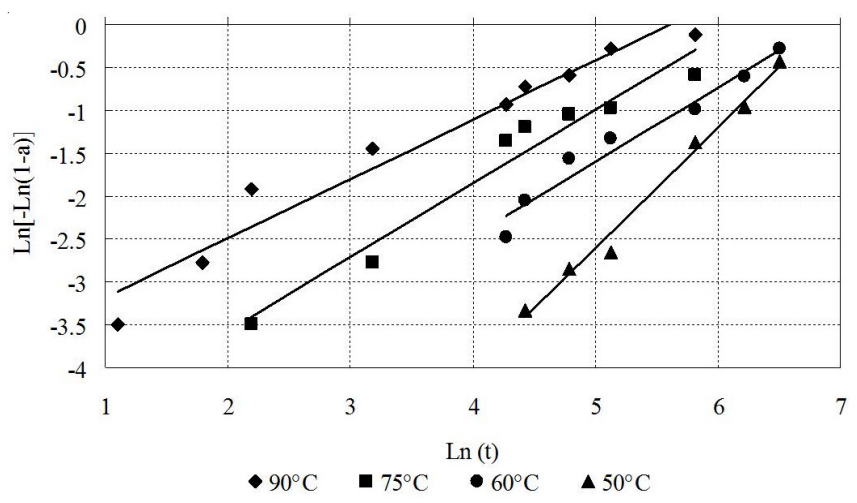

Fig. 3. Analysis of the reaction kinetics

zeolite tend to form on them which make these particles become crystalline core (Fig. 6). The reasons why crystalline growth process changed to liner-like growth $\left(\mathrm{n}_{2}=1\right)$ should be the tetragonal structure of Linde $\mathrm{F}(\mathrm{K})$ make the growth of crystalline tend to one direction and two other directions were limited.

Figs. 4 and 5 show the relationship between $\mathrm{k}, \mathrm{t}_{0}$ and absolute temperature. From these, we could get the activation energy of zeolite crystalline $\left(\mathrm{E}_{\mathrm{a}}\right)$ and nucleation $\left(\mathrm{E}_{0}\right)$. From Fig. 4, the activation energy of crystalline was $134.5 \mathrm{~kJ} / \mathrm{mol}$. Compared with $43-46 \mathrm{~kJ} / \mathrm{mol}$ of other zeolite ${ }^{11,12}$, our activation energy is relatively higher which advised that more energy were consumed during the formation process of Linde $F(K)$. The activation energy of nucleation $\left(E_{0}\right)$ means the difficulty of nucleation formation. Compared with other $62-70 \mathrm{~kJ} /$ $\mathrm{mol}^{13,14}$, our value $(85.4 \mathrm{~kJ} / \mathrm{mol})$ was still higher. As we know, one of important premises of nucleation formation is enough free silica and aluminum in alkaline solutions. Considering that fly ash particle was only one resource of silica and aluminum, the activation energy of nucleation should include the energy for dissolving of fly ash particles which make the activation energy of nucleation become higher.

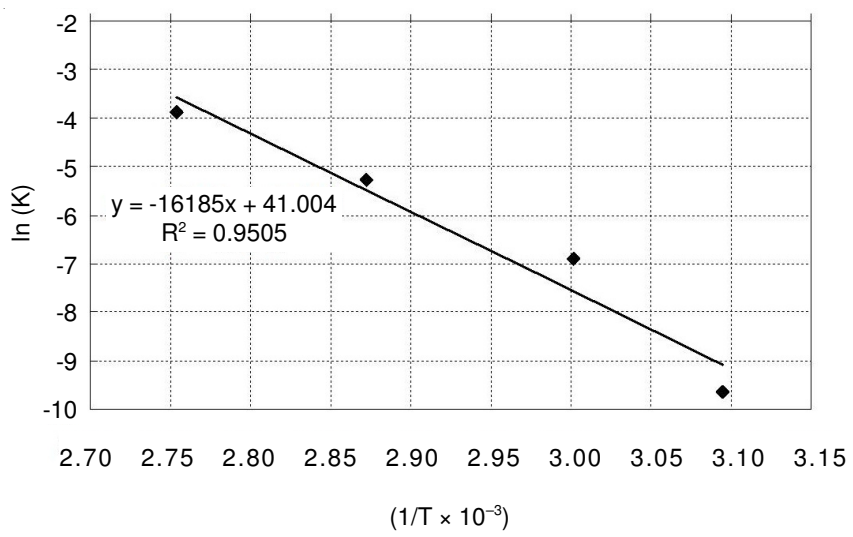

Fig. 4. Relationship between absolute temperature and reaction rate

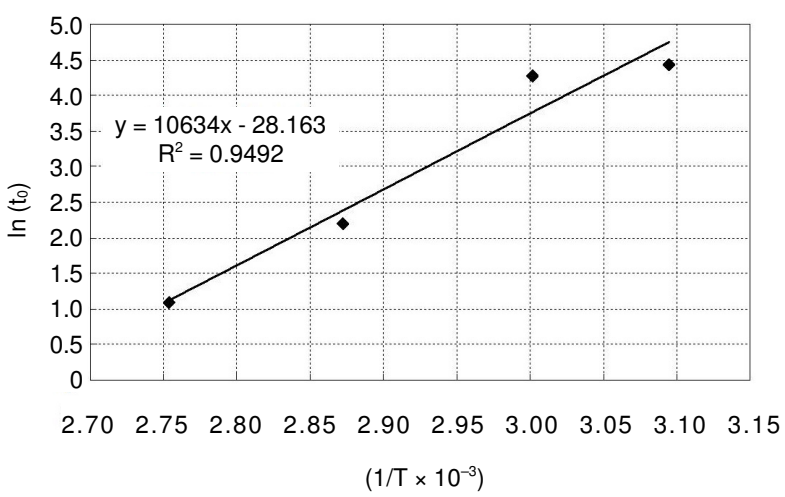

Fig. 5. Relationship between absolute temperature and introduction periods

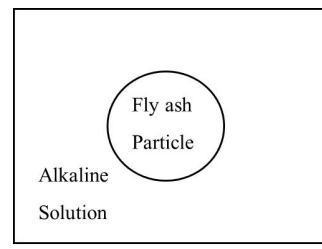

Before reaction

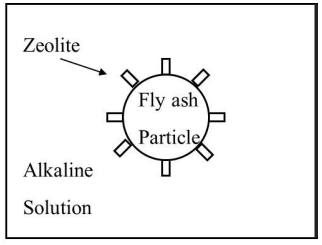

After reaction
Fig. 6. Heterogeneous model of zeolite growth

\section{Conclusion}

This paper described the kinetics analysis of fly ash based Linde $\mathrm{F}(\mathrm{K})$ zeolite by Avrami equations. The main conclusions were showed as below: (1) Linde F $(\mathrm{K})$ zeolite could be synthesized by the reaction of fly ash and potassium hydroxide solution at the temperature from $50-90^{\circ} \mathrm{C}$. (2) Temperature is one of important factors that affect the reaction process. The reaction rate could be enhanced with the increasing of temperature. (3) Avrami equations could be successfully used for the kinetics analysis of formation process of zeolite. According to the parameters in Avrami equations, the forming model of Linde type $\mathrm{F}(\mathrm{K})$ is heterogeneous and the crystalline is liner growth. (4) The activation energy of zeolite crystalline and nucleation was 134.5 and $85.4 \mathrm{~kJ} / \mathrm{mol}$, respectively.

\section{REFERENCES}

1. Greenpeace China, Toxic Coal Ash is China's Single Largest Source of Solid Waste, Available at http://www.greenpeace.org/eastasia/press/release/coalash-en-pr

2. S.S. Rayalu, J.S. Sapre and S.U. Meshram, Asian. J. Chem., 16, 717 (2004).

3. G. Akar, Ü. Ipekoglu and M.E. Ertem, Asian. J. Chem., 21, 2080 (2009).

4. C. Amrhein, G. Haghnia and T.S. Kim, Environ. Sci. Technol., 30, 735 (1996).

5. X. Querol, N. Moreno and J.C. Umana, Int. J. Coal. Geol., 50, 413 (2002).

6. S.D. Ghan, H.V. Bakshi and B.T. Bhoskar, Asian. J. Chem., 17, 634 (2005).

7. M. Khatamian and M. Dolatyari, Asian. J. Chem., 19, 5199 (2007).

8. F. Miyaji, T. Murakami and Y. Suyama, J. Ceram. Soc. (Japan), 117, 619 (2009).

9. M. Avrami, J. Chem. Phys., 7, 1103 (1939).

10. M. Avrami, J. Chem. Phys., 8, 212 (1940).

11. D.W. Breck and E.M. Flanigen. Soc. Chem. Ind., 47 (1984).

12. S. Tangkawanit and K. Rangsriwatananon. Suranaree J. Sci. Technol., 12, 61 (2004)

13. H.C. Hu and T.Y. Lee, J. Ind. Eng. Chem. Res., 29, 749 (1990).

14. A. Guatieri, J. Hanson and P. Norby. J. Phys. Chem. Mineral., 24, 191 (1997). 